\title{
Mass Customization based on the Product Life Cycle Theory
}

\author{
J.R. Yu \\ Department of Economy and Management Nanchang Hangkong University
}

\begin{abstract}
Due to development of information and manufacturing, many enterprises have the possibility to improve their technology enviroment and machine. More and more chinese enterprises would use advanced management theroy to maintain or gain the needed competitive advantages,. With the deepening of economic globalixation, the demand of costomer have changed to diverty and personality. Based on the the Product Life Cycle Theory, combining the mase customization, enterprises aims to solve customer problem.

KEYWORD: Mass customization; Product lifecycle; product lifecycle configuration
\end{abstract}

\section{INTRODUCTION}

Alvin Toffler was first posted the idea of Mass customization in the book of 《Future Shock》 (1970), after that Stanley Davis first used the word "Mass Customization" in his book 《Future Perfect $\rangle$ (1987), the beginning of research and practice to mass customization is after B. Joseph Pine II 《Mass Customization: The New Frontier in Business Competition 》 (1993), which was systematic expounded, now he also deeply pushed the theory of Mass, he published a lot of articles on the magazines about the Mass Customization.

\section{RELATED CONCEPTION}

Mass customization, is with the cost and speed of mass production and for individual customers custom Processing Single product to meet customers' individual requirements. Its core unites this contradictory opposites the mass production and customization through effective way to achieve both win. Mass customization aims is to make mass production of low cost, high efficiency advantage and highly differentiated product customization advantage is no longer a difficult choice not have both fish and bear's paw.

The concept of mass customization in general, can be divided into two categories: first broadly in a full sense on mass customization; Second narrowly on mass customization, mass customization is as a system. The former representative is Davis and Pine II. Davis defined mass customization as a kind of highly sensitive, flexible integration process, providing the ability to personalize products and services designed for each customer. Mass customization is considered to be a systematic point of view, which includes all aspects of product sales, development, production and transportation, covering the entire product life cycle. American Production and Inventory Control Society believes that "mass customization is a creative mass production, it can make the customers to choose a specific product they need within a large range of varieties, and thanks to mass production methods, the product cost is very low. " MC represents the adoption of selected refined work practices within revised business structures, leading to a highly adaptable, customer-centric, value-creating enterprise.

Some Chinese scholars also was intereting in researching mass customization. Qi Guoning consider that mass customization is that gather company, customers, suppliers and environment into one, under the guidance of systems thought, with the overall optimization ideas, leverage existing enterprise resources ,stand by standardized technology, modern design support methodology, information technology and advanced manufacturing technology, according to the customer's individual requirements, with production methods of largescale production of low-cost, high-quality and highefficiency to provide customized products and services.

Zhou bingHai made the following description on mass customization: Large-scale refers to the production of large quantities of products, customization is defined as the customer demand for our customers to provide individual services, mass 
customization is a comprehensive consideration of the environmental impact and market products to customers the individual needs of a modern highvolume manufacturing model.

Many scholars defined mass customization as a system that it can use information technology, a flexible structure and process to provide large scale production of products and services to meet customers' individual requirements. whatever with either definition.

The concept of product life cycle management first appeared in the economic sphere, proposed by the Dean, whose purpose is to research the product's market strategy. The product life cycle of their products in accordance with the evolution of the market is divided into the introduction, growth, maturity and decline phase.

After decades of development, the concept and content of the product life cycle in constant change. The early 1960s, American scholar Vernon (R.Vernon) and the small Welsh (LTWells) cycle analysis of products through international, put forward the theory of international product life cycle, also known as the product cycle theory. The key points are based on the dynamic changes in the product in international trade, and the product life cycle is divided into product innovation, product maturity and standardization of three stages. in the 1980s, product lifecycle management was introduced from the economy management to the project areas, which range of life-cycle management cover from the product needs analysis, conceptual design, detailed design, manufacturing, sales and service and even recycling. 1990s, the product life cycle has to be given to meet the sustainable development seeking meaning products developed new models. Thus, "Products Life Cycle "is an ambiguous theoretical concept, which reflects maturing product concept and development concept as awareness of sublimation.

\section{MASS CUSTOMIZATION LEVEL}

As the degree of customization needs of different customers, so there are different levels of mass customization.

Lampel and Mintzberg believes that there is the existence of a strategy continuum between a fully customized and fully standardized , and made mass customization five levels according to the degree of customer involvement in the design, that is fully standardized, subdivision standardization, customized standardization, custom tailoring oriented and fully customizable.

Gilmore and Pinen through empirical observation will be divided mass customization into four levels: Cooperation customization, adaptation customization, appearance customization and transparent customization.

Chinese scholars Ren-Wang Li and Qi Guoning put forward the concept Customer Order Discoupling Point, CODP. They believe that by different position CODP in the production process, mass customization can be divided to four categories by sales orders (Sale-To-Order, STO) or called stock production (Make-To-Stock. MTS), Assemble to Order (Assemble-To-Order, ATO), Order manufacturing (Make-To-Order, MTO), Order design (Engineer-To Order, ETO).

Shao Xiaofeng similarly divided custom into design custom, custom fabrication, assembly, customization; fan shuhai introduced the concept of similar CODP custom entry point (Customization position) that in the product or service value chain, first contains customized requirements point. This entry point can occur during the design phase, manufacturing stage, assembly stage and sales stage, but also can occur in the after-sales stage. The sooner the starting point, the higher the customer's custom requirements, implement custom difficulty is greater.

\section{MASS CUSTOMIZATION OF PRODUCT LIFECYCLE CONFIGURATION}

\subsection{Product lifecycle configuration conception}

The so-called product life cycle configuration is defined according to the customer's individual needs, built on product structure management, it makes the product configuration information can be created, recorded and modified, allow the product to be constructed in accordance with the special requirements, record a deformation was used to form the structure of the product.

We can see from the definition of the product life cycle configuration that has the following characteristics:

(1) Target of product lifecycle configuration is to meet the customer's individual requirements.

(2) Product lifecycle configuration consider not only the product configuration, but also other product life cycle process (product configuration is a special case of the product life cycle configuration).

(3) Product life cycle configuration involve different areas and stages of development of information management and coordination of the overall solution

(4) Product Lifecycle Configuration get not only the best customized variants product, also includes other considered product lifecycle process configurations.

\subsection{PLM technology system}

Numerous studies and applications show, PLM is an enterprise-class solution, not a single technology or 
application, but rather a complex collection of technologies and applications. Thus, PLM system must have a complete technology framework to regulate and describe the composition of the elements contained in the PLM system, and how to organize these constituent elements to make them run as a whole, collaborative completion of the function of the system. CIMData extensive research users, solution providers and a large number of studies to assess the basis for the commercialization of PLM solutions based on a multi-layered summed PLM technology system. The system described PLM solutions essential component elements and their relationships, and achieve levels depending on the constituent elements of PLM into key technologies, core functions, specific applications and business solutions four levels.

\subsection{Product Life cycle configuration system Framework}

In a product life cycle of configuration system, it also contains three parts:

(1) Input mdel: customer personalized demand, product family model, manufacturing process model, resource planning model and maintenance process model, supply chain models, and so on.

(2) Product Lifecycle Configuration system: This is the most central part of the product lifecycle configuration system, which according to the customer's individual requirements and related product life cycle model, using some algorithm, generate one or a set of optimal customized products and the corresponding considered variants of other products life cycle.

(3) Output model: Customer demand for variable products and other product lifecycle process considered appropriate configuration. When considering the number and type of product life cycle is not the same, the product life cycle configuration algorithm is different. Depending on the product life cycle considerations, we will configure the product life cycle divide into two categories: the transverse configuration of the product life cycle and the vertical product life cycle configuration.

When considering the number and type of product life cycle is not the same, the product life cycle configuration algorithm is different. Depending on the product life cycle considerations, we will configure the product life cycle divide into two categories: the resource configuration of the product life cycle and the supply chain product life cycle configuration.

Resource configuration life cycle refers to configuration from the direction of the product life cycle process to configure the product life cycle. It started from the customer's needs, taking into account the design and the resource of need (that is, the product configuration, product idea, test, design ) and other supporting processes, such as manufacturing process planning, manufacturing resource allocation, etc.. traditional product configuration is disigning product for mass customer, but mass configuration is the result of one or several variants to meet customer demand for products and product variants to achieve the appropriate other product lifecycle process.

Supply chain Lifecycle configuration refers to configure the product life cycle based on the value chain, from the customer needs, taking into account the product design and supply chain configuration. This sort lifecycle configuration aims to provides supplies network, by intergrating chain resouce products, improved products logistics to improve value of whole chain.

\section{CONCLUSION}

In the modern business environment, masscustomisation is a key strategy for an enterprise to achieve success. Mass-customisation is used to manufacture small amounts but a large variety of products to satisfy customer demands. This paper studies uncertain customer demand propose the concept of mass customization oriented product lifecycle configuration. Product lifecycle configuration refers enterprise configuration design personalized products for our customers ,through the product life cycle configuration, on the one hand, may be able to better meet customer needs; the other hand, receive personalized product can also get other considered product life cycle processes, thereby reducing the complexity of the management.

\section{REFERENCES}

[1] Eastwood M, Implementing mass customization. Computers in Industry, 1996, 30(3):171-174.

[2] PINE Ò B J. Mass customization: the new frontier in business competition. Beijing: China Peoples University Press, 2000( in Chinese) .

[3] Kay M. Making mass customization happen: Lessons for implementation. Planning Review, 1993, 21(4):14-18.

[4] ZHOU Bi nghai, SHI Haif eng, CAI Jianguo. Research on conceptual model of mass customization product ion. Journal of Shanghai University of Engineering Science, 2000, 14( 4) : 278 - 284( in Chinese)

[5] Ross A. Selling uniqueness. Manufacturing Engineer, 1996, 75(6):260-263. Joneja A, Lee NS. Automated configuration of parametric feeding tools for mass customization. Computers and Industrial Engineering, 1998, 3(3-4):463-469.

[6] SHAO Xiaofeng, WANG Rong, HUANG Peiqing et al. Research on postponement in mass customization with multiple product diff erentiation points. System Engineering - Theory M ethodology A pplications, 2001, (4) : 332 - 336, 341 ( in Chinese) 